\title{
DESCANSO DE CAMINANTES DE BIOY CASARES: CARTOGRAFIAR LA INTIMIDAD O DIBUJAR UN ROSTRO
}

\author{
Descanso de caminantes by Bioy Casares: mapping intimacy or sketching a \\ face
}

\section{RESUMEN}

El presente trabajo busca analizar Descanso de caminantes de Adolfo Bioy Casares desde los aportes teóricos de la geocrítica y los estudios de la intimidad. En esta obra del autor argentino, en gran medida desestimada por la crítica, se construye una máscara del yo a través de los espacios que la palabra hace aparecer. Una cartografía del territorio íntimo nos permitirá una mejor comprensión del diario en su totalidad y de la figura de autor que a él subyace.

\author{
Palabras claves: Bioy Casares - diarios - \\ intimidad - descanso - geocrítica
}

\section{ABSTRACT}

The present work seeks to analyse Descanso de caminantes by Adolfo Bioy Casares considering the theoretical contribution done by geocriticism and intimate studies. In this book, often underestimated by the critics, the Argentine author builds a mask for himself through the spaces created by discourse. A cartography of the intimate territory will allow a better comprehension of the diary as a whole and of the underlying author figure.

Keywords: Bioy Casares - diaries - intimacy geocriticism - descanso

\section{UNIVERSUM}

\section{SANTIAGO HAMELAU}

Centro de Estudios de Literatura Comparada "M. T. Maiorana", Facultad de Filosofía y Letras, Universidad Católica Argentina, Argentina.

\section{Correo electrónico:} santihamelau@yahoo.com.ar

ORCID: 0000-0001-7461-445X ResearchGate: Scholar.google: Academia.edu: 


\section{INTRODUCCIÓN}

Descanso de caminantes, de Adolfo Bioy Casares, es un libro extraño y en cierto modo eludible. Si bien pertenece a un género que hoy comienza a tomar relevancia - el diario íntimo-, integra el conjunto de manera ambigua, pues consta de una estructura desordenada y poco parecida al fluir de los días. En segundo lugar, el volumen que nos compete se muestra inferior (en tamaño, en complejidad, en estructura) a ese otro diario dedicado por Bioy a la figura de su amigo Borges. Por último, desde el punto de vista del contenido, Descanso de caminantes es un libro ácido y malicioso, que hiere con nombres propios y cuya lectura podría ser desaconsejada a fin de evitar la propagación de chismes. No obstante, hemos creído provechoso detenernos en este libro por los siguientes motivos. En primer lugar, porque formó parte de la última época de las obras de su autor, aquella ligada a la apertura de lo privado, que tuvo como objetivo consagrar un talento literario cultivado otrora con éxito. Esta estrategia de volcar lo íntimo sobre lo público no debe pasar desapercibida, ya que denota un interés de la época y evidencia en la obra de Bioy una voluntad de perpetuarse desde su figura autoral. Por otro lado, este espécimen de diario, pese a no ser brillante, sí permite más de una reflexión provechosa sobre el género al que pertenece. Nuestro trabajo se centrará sobre la categoría espacial, en base a los aportes de la geocrítica, los estudios de la intimidad, los estudios culturales y el análisis del discurso. La voz del diario de Bioy Casares propone un sujeto identificado con la elite que transita los espacios propios de su status socio-económico. Una cartografía de los escritos íntimos del autor argentino nos revelará, por una parte, los espacios de preferencia de este dandy hastiado $\mathrm{y}$, por otra, los lugares marginales que se cuelan para denunciar la pose. La trama del texto íntimo construye un personaje que oscila entre la ingenuidad de sus propios prejuicios de clase y la voluntariosa confección de una máscara poco útil. 


\section{DATOS TÉCNICOS}

Ante todo, es preciso aclarar algunas cuestiones prácticas o técnicas sobre Descanso de caminantes. Se trata de una obra procedente de los diarios de Bioy, más estrictamente de sus cuadernos de notas, y forma parte de un plan de publicación de sus papeles íntimos que él supervisó y que fue llevado a cabo por su albacea literario, Daniel Martino. El arco temporal que cubre Descanso de caminantes se extiende desde 1975 hasta 1989. Nos enfrentamos a una obra de vejez, tanto de edad como literaria. Bioy pasaba los sesenta años, ya en su tercera etapa de producción, como la denomina Nora Catelli (2012), "dedicada a la expansión pública de lo privado" (28). La cubierta anuncia que Descanso de caminantes son "diarios íntimos", cuando en realidad el prólogo escrito por su autor parece más exacto: "libros de brevedades" —o de "varia lección" como escribe Martino en el posfacio- en la misma tradición que Note-books de Samuel Butler o Las causeries de Lucio V. Mansilla. Más de un rasgo emparenta estas obras. Comparte con ellas el humor, la fragmentariedad, el ingenio que busca agradar al lector, el espectáculo de la curiosidad y un sentido del entretenimiento, atenuado sin duda por la también común tendencia a la digresión. En este sentido, quizás más valdría hablar de prosa diarística, en tanto el conjunto se presenta producto de un recorte que oblitera el origen, velando sus complejidades. Descanso de caminantes propone una deriva en la voz que tiende menos al acontecimiento que a la memoria o, para decirlo de otro modo, al acontecimiento del recuerdo, una voz con una propensión retrospectiva que desdeña las situaciones cotidianas, así como el ahora y el lugar de la escritura. Los temas tratados por Bioy Casares son su propia vejez, su lumbago, sus problemas de próstata, los sueños, las anécdotas con mujeres, las anécdotas de escritor, las consideraciones ensayísticas sobre la escritura y la literatura, las curiosidades léxicas al modo del diccionario de Flaubert; por último, sus amigos y su familia en bastante menor proporción. Este libro es una colección de pensamientos o de anotaciones para prevenirlas del olvido, del mismo modo en que Samuel Butler había sentenciado que "nuestros pensamientos vuelan tan rápido que uno debe dispararles" (2002: 1). 


\section{ESPACIO=EVIDENCIA: LA MATERIA}

$\mathrm{Si}$, como escribe Bertrand Westphal, "el espacio parece señalar la evidencia" (2015: 27), en el caso de un diario necesitaríamos concentrarnos sobre el primer espacio que ofrece el texto y que es anterior o colindante al significado. Nos referimos al papel, cuaderno o superficie sobre los que diversos materiales inscriben un lenguaje. El estudio del diario es, en primera instancia, el estudio del manuscrito, es decir, de una palabra hecha acto pictórico, de una palabra que coexiste con dibujos, con objetos, con actos. El artista Joseph Beuys decía que, cuando firmaba, él sentía que estaba dibujando. Por otro lado, los diarios abundan en notas, elucubraciones o juicios que difícilmente puedan ser interesantes. Estas páginas íntimas no aspiran a ser un libro, constituyen más bien un proceso, donde el libro adquiere carácter de desprendimiento. Analizar manuscritos raramente es posible, ya que no es frecuente que se tenga acceso a ellos. El escollo mayor, sin embargo, reside en la extensión de los diarios que requieren tiempos de trabajo excesivamente prolongados. Las versiones publicadas, en cambio, que se acotan o expurgan, muestran con mayor fuerza su carácter de construcciones autobiográficas o editoriales, como ha sucedido, por ejemplo, con el caso de Alejandra Pizarnik o como sucede con Bioy, que personalmente juntó los fragmentos para armar Descanso de caminantes. Sobre esta obra, es preciso decir que se trata menos de un diario que de un libro. El verdadero diario se encuentra en los incontables cuadernos de Bioy que ascienden a muchos miles de páginas con sus digresiones, erratas, palabras ininteligibles, espacios en blanco, etc. Hay un gesto común. Descanso de caminantes, por el contrario, es una selección deliberada que obedece al gusto y los caprichos del autor y encuentra su cohesión y sentido en esta disposición consciente que discriminó entre los materiales incluibles y descartables. 


\section{EL SNOB, UNA FIGURA DE AUTOR}

Si nos adentramos en el contenido del libro, para continuar con el método, nos preguntaremos lo siguiente: ¿qué evidencias nos señala la geografía del diario de Bioy? La trasposición escrita de su recorrido vital crea un personaje que es una red de símbolos y donde el espacio representa una coordenada de gran relevancia. Una breve lista de lugares puede ser la siguiente: el barrio de la Recoleta, la calle Alvear y su puesto de diarios, el departamento de la calle Posadas, el bar de la Biela, la estancia Rincón Viejo en Pardo, el Jockey Club del que Bioy formaba parte, las cenas de la Cámara del Libro, los viajes al viejo continente, etc. Se descubre inmediatamente la cartografía de un espacio de privilegio, al que se agregan espacios imaginarios como las lecturas - en general europeas, por ejemplo, Lord Byron o Benjamin Constant - o la mención de apellidos ilustres, que traen consigo el peso de las genealogías estancieras. El yo de Bioy instaura para sí y para los otros —a su turno aceptados y excluidos - los códigos culturales de su clase y con ellos las divisiones correspondientes entre alto y bajo, educación y guaranguería. Estos estándares son fronteras que constantemente deben cruzarse, que muy frecuentemente se trastocan y como consecuencia se vuelven tangibles, produciendo momentos de tensión en estas anotaciones más bellacas que ingenuas.

Bioy se configura como un ser imperturbable, un snob como, advierte Mariano García (2017), dandy curioso capaz de sondear lo que le es ajeno, siempre sin esforzarse. Un episodio particularmente vívido es el de la estudiante $\mathrm{M}$, que escribe una tesis sobre Bioy y que luego de varias peripecias termina instalándosele en la casa. Él anota: "Silvina, que al principio le encontraba virtudes, tampoco la aguanta y la llama Bartleby. Yo no le perdono que me obligue a ser guarango con ella" (2001: 32). Al Bioy discursivo le molesta tener que ser "guarango", primero porque debe adoptar una actitud extraña a su posición de clase y segundo porque ello implica un condicionamiento del medio, una forma en la que el yo se ausenta de su libertad. De esta forma, Bioy 
no puede ubicarse por encima del mundo sino que se ve forzado a ponerse a la altura de aquellos a los que considera explícita o implícitamente inferiores. Nuestro autor se muestra fascinado por lo abyecto y la betise, pero sin reconocérselo a sí mismo. Curiosamente para un diarista, pocas veces vuelve sobre su metodología, casi nunca se detiene a pensar sobre su actividad como redactor del diario. Si reflexiones metalingüísticas hipotéticas se encuentran en el volumen original de papeles privados, Bioy ha decidido expresamente no mostrar este costado. Lo que sí ha visto la luz editorial tiene un tono retrospectivo, su cronología solo a grandes rasgos sigue la línea vital de Bioy y genera una impresión de desorden. Es muy probable que el material del que procede la selección editada haya tenido anotaciones con una menor distancia entre los presentes del enunciado y de la enunciación. Las observaciones del volumen podrían ser reordenadas sin mayor impacto sobre el todo, lo cual parece encontrar causa en la trasposición de diario a libro.

La imperturbabilidad de Bioy, como sujeto discursivo que se construye desde la figura del $d a n d y$, llega al límite en el conocido episodio del Falcon verde, durante los años de la dictadura, un relato que de nuevo desborda de ingenuidad al tiempo que la historia le devuelve toda su violencia intrínseca. Las circunstancias obligan a Bioy a presenciar una persecución a tiros de la policía. Más tarde, el autor se entera de que se trató de un fusilamiento. Bioy describe sus acciones: intenta tirarse al piso, pero teme no poder levantarse o ensuciarse la ropa, por lo que cambia de vereda y permanece al margen, buscando entre tanto a la amante con la que tenía una cita. Cuando la encuentra, da la vuelta manzana con ella y luego le pide "amablemente" a un policía si puede retirar su auto, es decir el de Bioy, estacionado de manera inconveniente en el lugar del altercado. La ironía del adverbio es tan asombrosa que vale interrogar si realmente tiene otra cara. La frialdad del diarista parece ingenuidad mal disimulada: insinúa su nerviosismo cuando no puede poner la llave en la cerradura del auto y reconoce que el episodio le deja un sabor triste. Bioy teme reconocer que es humano, pero gracias a ciertos detalles acaba por contradecir la indulgente dedicatoria de Martino cuando remarca que el volumen "nunca cede a la melancolía" y que está dotado de "esa amable sinceridad que, como 
quería Rousseau, puede proponer inexactitudes para mejorar una anécdota, pero nunca para encubrir un vicio o para fingir una virtud" (2001: 506). Las inexactitudes, que al lector no le son cuantificables, dejan pistas de aquella máscara destinada a purificar la realidad y volverla inofensiva. Se sabe que la risa hace lo mismo, nuestro escritor satírico lo tenía claro.

\section{EL PREJUICIO COMO JERARQUÍA ESPACIALIZADA: ¿DÓNDE QUEDA EL YO?}

Discriminar a los estúpidos, a los guarangos o maleducados requiere prejuicios que marquen estándares. La adecuación o no a ellos marca el límite entre el "nosotros" y el "ellos". Bioy se muestra afecto en el diario a esta taxonomía social. Aun así, hay una categoría en la que falla todo el mundo, incluso el diarista: la propiedad en el uso de la lengua. Bioy se divierte registrando los usos correctos e incorrectos del español, así como los de frases comunes en otras lenguas. A veces él mismo se encuentra en falta, a veces son miembros de su clase socio-cultural, pero en general se trata de personas menos instruidas que él, lo cual refuerza la mirada altanera y antipática que el yo del discurso pone de manifiesto en el transcurso del libro. Transcribo una de las tantas listas que el lector podrá hallar: "Modos de decir argentinos: A Miguel Casares le oí decir erudicción. A Cali F., le oí decir Prus por Proust; bet seller por best seller. A medio país le oí decir cónyugue. (...) Yo (si me descuido) digo cabresto por cabestro. (...) Los que decimos recao (por montura) decimos recado (por encargo)” (2001: 147). Bioy Casares reconoce aquí, en primera medida, su espacio de pertenencia ligado al campo - "los que decimos" en oposición a quienes no dicen - y admite entre paréntesis el estado de observancia que delata la pose. La norma lingüística, utilizada en este caso como patrón de inclusión/exclusión, también se fractura, por ejemplo, a la muerte de la perra Diana: "Me ha maravillado la delicadeza de la gente (gente de expresión por lo general defectuosa, y aún torpísima) para referirse a ese hecho. Alguien que no sabe hablar, que dice 'Me voy de un santo a comprar un Chubut' por 'Me voy de un salto a comprar un yoghurt', comentó 
'La perra se nos fue'. Qué bien: el 'se nos fue' en lugar de 'se murió, que yo hubiera utilizado' (2001: 71-72). El efecto es de insospechada ternura, como si el dandy rindiera por un segundo la máscara. Por último, la escritura de Bioy jamás se permite palabras soeces o improperios. Sin embargo, cita expresiones de igual tenor dichas por otros, como si le divirtiera el registro de la fauna local. Este fenómeno también lo vemos en el libro autobiográfico De jardines ajenos, en los que se anotan versos y prosas indecorosas y hasta pornográficas de supuesta atribución anónima. Este tipo de inventarios lingüísticos, que pueden perfectamente parangonarse con los de Flaubert como antecesor de Bioy, hacen hincapié sobre una actitud que tanto el escritor francés como el argentino comparten: el rechazo categórico de la bêtise humana.

En su mayoría, la escritura de este volumen produce un efecto de vago humorismo, en el sentido que le da a esta palabra Pirandello: los dardos se lanzan al aire para practicar puntería, pocas veces el odio está dirigido o motivado. Posterior al chiste, el sentimiento de lo contrario, como formuló el dramaturgo italiano, tarda en advenir. Giordano $(2006,156)$, refiriéndose a las Memorias de Bioy, a las que califica de dispersas y faltas de interés literario, subraya el capítulo en el que el autor despliega su virulencia en contra de Victoria Ocampo, su cuñada. Este fenómeno también lo encontramos en Descanso de caminantes, cuya ironía o comicidad llegan a su clímax producto de la referencia a figuras odiadas y/o burladas. La ciega inconformidad que trasmite este libro - a excepción de algunos episodios - se dirige a todo el género humano. El yo se distancia a través de una maniobra que al tiempo que lo eleva empoderándolo con el discurso, también lo aleja y lo aísla. Uno se pregunta si la máscara del dandy esconde la del excluido. Giordano (2006), por ejemplo, analiza el perfil de Bioy en sus escritos autobiográficos desde el psicoanálisis y concluye que el donjuanismo y la misoginia son consecuencia del abandono materno.

Hay un episodio que quizás ofrezca una respuesta al enigma planteado. El yo discursivo de Bioy comienza, como ya es usual en él, un relato que se remonta a la infancia. De pequeño admira condecoraciones en el Palais Royal con su padre, quien le explica el valor simbólico de la Legión de 
Honor. El niño primero quiere que se la compren, pero el padre explica que es preciso ganársela. Bioy entonces sueña con ella, la anhela por motivos poco honorables: la condecoración es chic, implica un trato preferencial a quien la porta. Más tarde anota una observación muy suya: incluso si se la dieran, sería de categoría inferior, porque diferirían las condecoraciones que se dan a los franceses de las que obtienen los extranjeros. En 1979, el diarista se entera de que el embajador ha pedido una condecoración especial para él. El dandy, antes de emocionarse, se previene: duda de que a él le den la Legión de Honor, como a otros escritores a los que secretamente envidia (Borges, Mujica Láinez, Sábato). La conclusión es previsible, el relato sirve para abonar la sorpresa del lector, en nada sorprendido, de que a Bioy le confieran, en efecto, la ansiada condecoración. La estocada final del episodio se produce en otra anotación muy posterior, en la que Bioy busca ponerse su Legión de Honor y no la encuentra entre los cajones.

La imagen de Bioy en el libro se vuelve patética en virtud de este exhibicionismo pueril que menos ennoblece de lo que empantana. Si la bêtise podría definirse como la utilización de recursos excesivos para tareas triviales, como les sucede a ciertos personajes en las novelas de Balzac o Flaubert, entonces Bioy es en realidad un poco presa del concepto que monitorea obsesivamente en los otros. La ironía tiene su costado amargo, porque hay dos rostros que temen encontrarse: el Bioy biográfico — que es desde luego una hipótesis de lectura- y el Bioy discursivo del diario que es en alguna medida su espejo. La mirada inmisericorde del Bioy biográfico debería en algún momento ver su reflejo y conmocionarse de alguna manera, como le sucedió a Dorian Gray con su cuadro. El lector espera ese instante en el que el sujeto rompa con esa tranquilidad artificial de una vida sosegada, casi sin quejas. 


\section{EL DIARIO: OCULTAR Y REVELAR}

El diario, como espacio discursivo, es lingüísticamente sesgado y acoge la diversidad, en función del tamiz o la jerarquización del diarista. Westphal (2015: 27) propone un estudio de las interacciones de los espacios, haciendo hincapié en una concepción plural y plurívoca del lugar. Para ello, utiliza la imagen del archipiélago. No hay necesidad de hurgar mucho para hacer emerger el archipiélago en el diario, puesto que la escritura de este género es una acumulación perdida de islotes vinculados por el tiempo de una subjetividad. El diario propone un cruce entre lo ficcional y lo factual, cuyas fronteras a los efectos formales parecen indiscernibles. Los límites, aunque difusos, conservan las huellas de un proceso de redundancia de lo vital en lo escritural. Una especie de literalidad tramposa, un agua clara que en el fondo está sucia, porque esa redundancia ocurre de manera parcial - no todo lo que sucede se escribe - y en función de una imagen de autor o una construcción de autor que se pone en acto al momento de escribir.

Todo diario íntimo conserva la misión de revelar y de ocultar. El tiempo se abre paso en el diario para crear el espacio de lo íntimo. La contienda aparece entre aquello que se busca expresar y aquello que es expresado, es decir, entre el diario y la intimidad. Descanso de caminantes, que es un diario de escritor, presenta una persona - en su acepción antigua, máscara de actor - del individuo real. La escritura crea una voz que hace presente a un sujeto junto con un paisaje de sí. Nos apoyaremos en la definición que Michel Collot ofrece de paisaje: "no es el país, sino una cierta imagen del país, elaborada a partir del punto de vista de un sujeto" (2015: 69). Un hombre también puede ser un paisaje, porque su rostro está hecho de líneas escritas. La pregunta es si las líneas coinciden con el rostro, más en nuestro caso si consideramos que uno de los atributos de un dandy es el del ocultamiento o el disfraz. El diario, por otro lado, realiza una tarea imposible, pues la intimidad inalcanzable para el propio sujeto es una forma de utopía vuelta escritura, en la que la letra ata lo íntimo a un contenido. 
Descanso de caminantes es un libro que, puesto en el cruce entre la exposición pública y privada, trafica con secretos de otros. Bioy explota en este texto las intimidades ajenas; a los acontecimientos guardados por la historia, él los vende en tinta y papel. Es un libro en muchos casos para herir y llamar la atención, pues torna la vida privada en espectáculo verbal. El diario íntimo en la actualidad no se encuentra lejos de esa forma que Paul de Man (1979) había asignado a la autobiografía: la prosopopeya. Los papeles íntimos, y en el caso de Bioy Casares es más que evidente, están muchas veces pensados para el ámbito público, con el objetivo de perpetuar al escritor o desplegar su vanidad. Tanto una como otra actitud se encuentran estrechamente ligadas con el horizonte de cualquier diario que es la muerte de su autor, como expuso Philippe Lejeune (2009: 187). Este horizonte es invisible, una previsión racional pero callada de la que Descanso de caminantes no se encuentra exento. Este es un libro fuertemente atravesado por la muerte y el temor de la muerte. Su autor se muestra notablemente afligido por el paso de la edad, los achaques, las operaciones de próstata, las visitas médicas, el lumbago, el decreciente interés que muestran las mujeres por él, etc. Hay también una ausencia que Daniel Martino nos indica en el posfacio: la escritura diarística de Bioy, de la cual Descanso de caminantes es solo un fragmento, se fue haciendo más escueta con el tiempo, producto de la muerte de sus amigos e informantes, junto con el progresivo alejamiento de Borges. La pulsión de muerte en el diario es el vestigio de una lucha: en tanto que archivo (Derrida 1997: 20), es un centinela en contra de la disolución y el olvido.

\section{CONCLUSIÓN}

En suma, Descanso de caminantes despliega la categoría del espacio en múltiples acepciones. En primer lugar, hacia el interior del diario hemos encontrado una redundancia entre los espacios escriturales y aquellos transitados por el personaje real Bioy Casares. Este mapa con sus ubicaciones configura un lugar de enunciación de prestigio junto al que se establecen 
fronteras rígidas pero permeables de exclusión. No obstante, los límites se corren y el yo que construye este paisaje imaginario jerarquizado se esfuerza por ubicarse en el rol de árbitro. Aún así, algo falla. "Un esnobismo ciego, no reflexivo, resulta trágico", comenta Mariano García (2017: 1). La aparente imperturbabilidad del dandy se ve mellada por una realidad impura que le obstruye la libre circulación: la escritura acusa recibo de las molestias del cuerpo, del desgaste de la edad. Si a un tiempo Bioy Casares busca estar por encima, también es lícito proponer que teme encontrarse por fuera de sus propias lógicas de exclusión. El diario íntimo sirve, en este caso, como receptáculo de las contradicciones del ánimo observador de un hombre que permanece, con la excepción de algunos odios definidos, esencialmente opaco al lector. Para concluir, vale una reflexión final en torno al diario y la geocrítica. Michel Collot escribe:

\begin{abstract}
Para Kenneth White, la cultura "tiene como base el vínculo entre el espíritu humano y la tierra, ella constituye su desarrollo en los planos intelectual, sensible y expresivo". Ahora bien, la civilización moderna parece haber perdido esta base que es preciso reconquistar para reconstruir un mundo habitable. Y a ello puede contribuir la literatura, siempre que no se repliegue en la "cerrazón del texto" [clôture du texte]: ella no es solamente un arte del lenguaje, como lo sostenían en los años setenta el textualismo y el formalismo; ella implica una visión del mundo y requiere "una poética posmoderna, es decir, ni del yo, ni de la palabra, sino del mundo". (2015: 70)
\end{abstract}

Creemos que se puede pensar el diario como un discurso íntimo que ha entrado de lleno en la cultura para habitarla. El auge actual de este género y de los estudios dedicados a él hoy presenta la siguiente pregunta: ¿qué es necesario que sea habitado o qué hay de deshabitado en nuestra posmodernidad que necesita tanto de la palabra, para establecer un vínculo entre la humanidad, la subjetividad y un espacio real e imaginario como la intimidad? 


\section{REFERENCIAS}

Bioy Casares, Adolfo. Descanso de caminantes. Buenos Aires: Editorial Sudamericana 2001.

Butler, Samuel. Note-books. Project Gutenberg. 2002. Online: https://www. gutenberg.org/files/6173/6173-h/6173-h.htm

Catelli, Nora. "Dos hombres solos hablan: Borges de Bioy Casares". Variaciones Borges, 34, 2012: 27-37.

Collot, Michel. "En busca de una geografía literaria". Espacios, imágenes $y$ vectores: Desafios actuales de las literaturas comparadas. García, Mariano, Punte, María José, Puppo, Lucía (comps.). Buenos Aires: Miño y Dávila, 2015: 59-75.

De Man, Paul. "Autobiography as De-facement", en $M L N$, Vol. 94, No. 5, Comparative Literature, (Dec., 1979): 919-930.

Derrida, Jacques. Mal de archivo. Una impresión freudiana. Madrid: Trotta, 1997.

García, Mariano. "Ese jardín vedado al medio pelo. Capítulos del esnobismo en Victoria Ocampo, Adolfo Bioy Casares y Jorge Luis Borges", Cuadernos LIRICO [En línea], 16 | 2017, Puesto en línea el 23 septiembre 2017, consultado el 08 mayo 2019. URL: http://journals. openedition.org/lirico/3590; DOI: 10.4000/lirico.3590

Giordano, Alberto. Una posibilidad de vida. Escrituras intimas. Rosario: Beatriz Viterbo, 2006.

Lejeune, Philippe. On Diary. Estados Unidos: University of Hawaii Press, 2009.

Westphal, Bertrand. "Aportes para un enfoque geocrítico de los textos". Espacios, imágenes y vectores: Desafios actuales de las literaturas comparadas. García, Mariano, Punte, María José, Puppo, Lucía (comps.). Buenos Aires: Miño y Dávila, 2015: 27-57. 